\title{
INSTITUTIONAL GASIFIER STOVE: A SUSTAINABLE PROSPECT FOR INSTITUTIONAL COOKING
}

\author{
Er. Bhakta B. Ale, Ph.D., Er. Nawaraj Bhattarai, Jitendra Gautam, Pradeep Chapagain, \\ Pushpa K.C
}

Department of Mechanical Engineering, Pulchowk Campus, Institute of Engineering, Tribhuvan University

\begin{abstract}
Gasifier stove can act as a simple and very important device for an energy sector which can improve cooking and kitchen environment. It would be more worthy if it is used for roadside hotels, hostels, schools, barracks, etc. where cooking is used for a large number of people. Taking this into consideration, a study had been conducted by studying the performance of the existing modified AIT model gasifier at NAST and then fabricating new institutional gasifier with further modification. The newly fabricated gasifier has better thermal efficiency compared to that of the modified gasifier present in NAST when tested with different types of fuel. The newly fabricated gasifier (IGS-2F) has an average efficiency of about 19\% compared to modified gasifier (IGS$2 \mathrm{M})$ which has an average efficiency of $17 \%$. The pine cone has the highest efficiency followed by rice husk briquette, maize cob and wood chips respectively for IGS-2M. The smoke index test was done and compared with the standard smoke scale to find the extent of pollution and it is found at acceptable limits after the gas production has started. The socio-economic analysis shows that IGS-2F is feasible having a payback period of about 14 months and the cost benefit ratio of 4.0 .
\end{abstract}

Key Words: Institutional gasifier, Thermal efficiency, Smoke index and Socio-economic analysis

\section{INTRODUCTION}

Biomass fuel is predominantly used in rural areas of developing countries. Even though it is essential for survival in many places, its use is fraught with problems. Fuelwood stoves are typically inefficient in comparison to modern stoves that burn gaseous fuel. In addition to fuelwood, crop residues and dung are also used. Biomass/ wood fuel is being gathered free of cost manually outside the market system and thus regarded as cheaper source of energy in most of the rural areas. Historically, Nepal's rural population has been meeting the energy need from the traditional sources like fuelwood and other biomass resources. The economy of the rural population is largely based on agricultural activities. Biomass resource play major role in the overall energy sector of Nepal and will continue to be the main source of energy for most of the rural areas at least for some future decades.

For the poorer half of humanity who must rely for their basic energy needs on biomass (fuelwood and charcoal when these are available, straw crop residues) and the time when firewood is scarce - the efficiency of fuel use, is of considerable importance. Most traditional biomass stoves are not very efficient for heat transfer; in fact, in controlled tests they have been found to use up to six or seven times more energy than non biomass stoves. In a study it was found that one-third of all household energy expenditures was on fuelwood or charcoal and that energy expenditures accounted for about one-tenth of all household expenditures. The urban poor sometimes spend as much as one-fifth of their income on energy, more than half of it on biomass 
fuels; for the rural populace, the time and effort needed to collect fuel exacts significant costs, and hundreds of millions of them now have to rely on biomass fuels even less desirable than wood. (Shrestha et.al., 2005)

Approximately $86 \%$ of people in Nepal still use traditional mud-cooking stoves. The stoves are inefficient and use excessive firewood that has to be collected from the forests, mainly by women and children. Domestic chores take up a lot of children's time, particularly girls, causing them to miss school so that their education is held back. Due to these problems, the government has been supporting a program to introduce improved cook stoves (ICS). The general objective of this program is to establish a sustainable framework and strategy to make technically available and socially appropriate ICS in rural communities based on local capacity building and income generation. This program has been currently promoting ICS in 33 mid-hill districts of the country (Center for rural technology, Nepal, 2006).

Biomass gasifier has been developed in different parts of the world since nineteenth century. But the gasifiers fabricated so far are generally too big for domestic uses. A downdraft gasifier stove for domestic cooking has been manufactured in China. In Nepal, Nepal Academy of Science and Technology (NAST) has developed a briquette gasifier stove by adopting the design of Asian Institute of Technology (AIT), Thailand (Singh and Shakya, 2001). Similarly, Basnyat (2004) has fabricated a gasifier primarily intended for cardamom drying. Simkhada (2005) has also developed an institutional gasifier adopting the design of China.

Prevailing traditional cooking stoves (using fuel wood) are typically inefficient in comparison to modern stoves that burn gaseous fuel. These stoves use fuel wood, crop residues and dung. Biomass/ wood fuel is being gathered free of cost manually outside the market system and thus regarded cheaper source of energy in most of the rural parts. Biomass resource play major role in the overall energy sector of Nepal and will continue to be the main source of energy for most of the rural areas at least for some future decades. But using inefficient stoves will lead to the wasteful use of the biomass fuel resulting in health problems and rapid deforestation. Hence, to overcome this challenge there have been recent developments in the field of cooking stoves, with the front runner being the institutional gasifier stove, especially well apt for the institutional sectors and if trimmed down will also be successful for the domestic cooking purpose.

Gas, electricity and liquid fuels being clean and efficient are preferred for cooking, however the access to such energy is limited for majority of the population in Nepal, and they are compelled to use wood as fuel in traditional manner. Traditional combustion of biomass material produces low conversion efficiency and high emission leading to health problem and deforestation.

In the last few decades many improved wood stoves have been developed in different parts of the world. Huge resources have been invested to replace the traditional stoves by improved cooking stoves in Nepal too. It is possible to produce gas from wood in practice. Therefore, biomass gasifier has been developed in different parts of the world since nineteenth century. Many countries of the world are working to build institutional type of gasifier for large and continuous cooking purpose. The Asian Institute of Technology, Thailand is working in the field to build an institutional type gasifier for cooking purposes for hostels, roadside restaurants, barracks etc. In Nepal, NAST has developed a briquette gasifier stove by adopting the design of Asian Institute of Technology, Thailand (Singh and 
Shakya, 2001). As briquettes are not easily available in rural areas of the country, hence this study was in need for modification and use of other biomass resources.

\section{OBJECTIVES}

The main objective of the study is to fabricate and evaluate the performance of cross draft gasifier for institutional cooking purpose. The gasifier fabrication is done by the process of adaptive research to meet the cooking requirement for mass cooking in canteens, hostels, hospitals, police and military barracks.

The specific objectives are:

- to improve/modify the existing gasifier of NAST in order to increase its efficiency,

- to fabricate with modification a commercial gasifier stove using locally available materials,

- to study the performance of the fabricated gasifier,

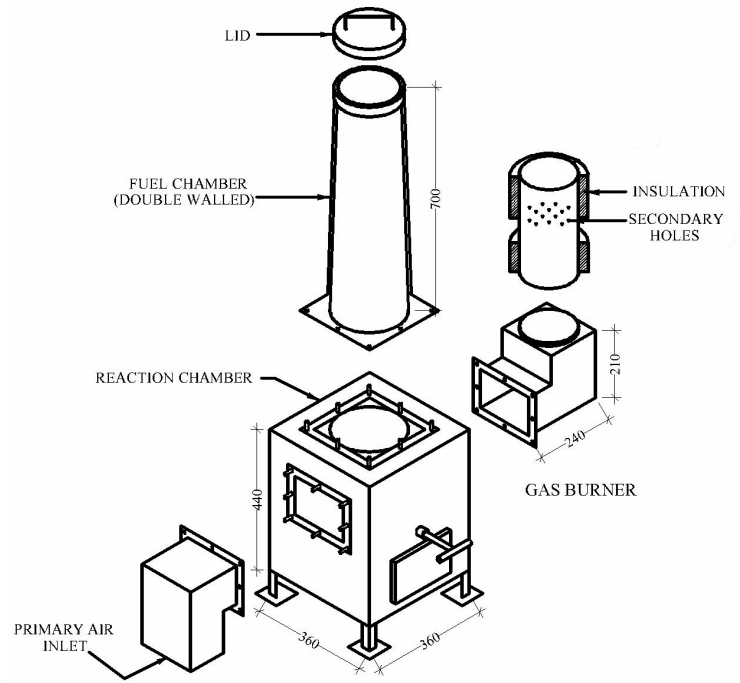

- to compare the efficiencies of gasifier using various biomass fuels available in the rural areas of Nepal,

- to evaluate the socio-economic analysis of the gasifier stove against traditional cooking stove.

\section{APPARATUS AND METHODOLOGY}

The stove is basically a small natural draft, cross-flow gasifier coupled to a gas burner. The primary air enters the hot fuel bed on one side, and the gas leaves from the opposite side. The gasifier-gas burner is a component of the stove (which consists of five main parts attached together by using bolts and nuts. Above the gas burner, connected with it, is a pot supporter on which the cooking pots are placed.

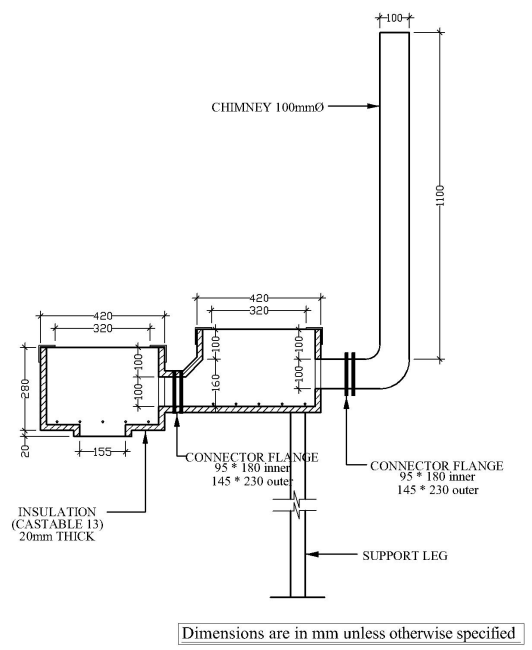

Figure 1 Main components of institutional gasifier $(I G S-2 F)$

The primary purpose of this project was to test a biomass gasifier for the commercial purpose. But for this, an efficient design of a gasifier is required. The design of this biomass gasifier involves large number of optimizations in different parameters. The outer structure just seems to be bulky, but 
when dealing with its importance and uses, the bulky nature will be dominated by its well-finished and branched structure Before the fabrication of the new gasifier it was felt necessary to rejuvenate the existing institutional gasifier at NAST. The methodology that was employed in this study is summarized as follows:

\section{Modification of the existing gasifier stove}

The primary task with the existing gasifier was to investigate the design configuration

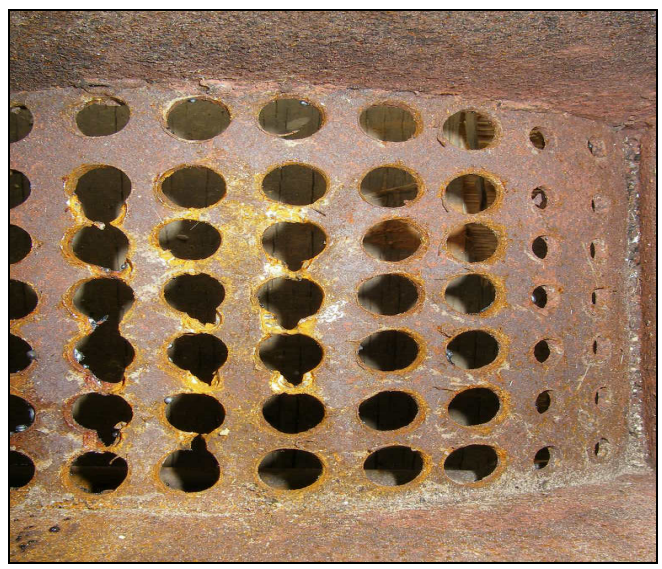

Figure (a) and examine its previous performance data. After an investigation, it was found that there were no past written data or any analysis of the performance of existing gasifier at NAST. After inspection of the gasifier it was found that the holes for air inlet and producer gas outlet as shown in figure (a) weren't sufficient to supply adequate amount of air for the gasification process inside the reactor and then the producer gas could not pass towards the stoves freely, resulting the poor performance of gasifier.

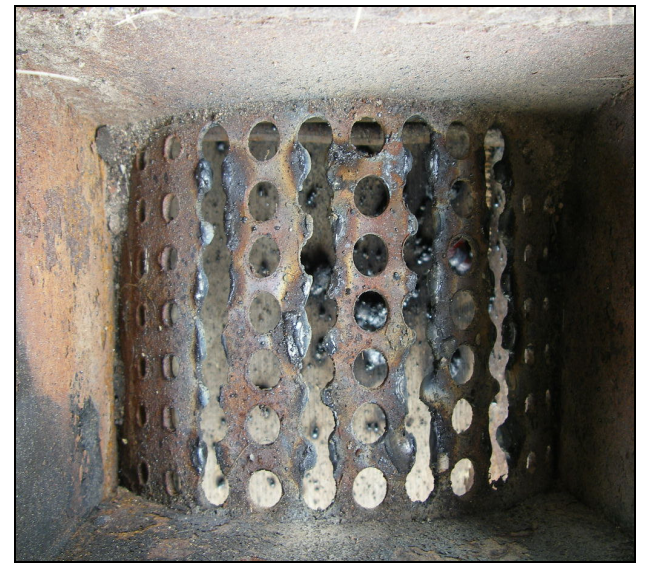

Figure (b)

Figure 2 Primary air inlet of gasifier stove (a) initial (b) modified.

Hence, the necessity to improve the design of the gasifier was imminent. So, the holes of air inlet and producer gas outlet were slotted with welding machine and vertical slots were made as shown in figure (b). Other repair and maintenance was also done; such as the insulations in the joints were placed properly, the ash remover or ash removing handle was made new for convenient performance and easy removing of ash.

\section{Fabrication of the new gasifier stove}

Reviewing the available literature, the AIT model is identified as a relative appropriate model for the institutional cooking. This gasifier was fabricated using locally available material and local technological capability. The fabricated

gasifier was tested for different fuel types and their efficiency. The cross draft gasifier was fabricated with the help of figures available of AIT design and selection of better design procedure and parameters.

\section{Materials and equipment required}

The different materials required for the full fabrication of the AIT design gasifier are as follows: Plain mild steel sheet, glasswool insulation, iron in different form, galvanized iron sheet, round steel bars.

The equipment required for testing of the gasifier stove are very sensitive ones. The equipments necessary for the different 
purposes are digital thermometer indicator (HIOKI, range: $50^{\circ} \mathrm{C}-800^{\circ} \mathrm{C}$ ) for temperature measurement of the fuel ignition, digital thermometer indicator (HIOKI, range: $50^{\circ} \mathrm{C}-400^{\circ} \mathrm{C}$ ) for surface temperature measurement, digital thermometer indicator (OMEGA, range: $50^{\circ} \mathrm{C}-800^{\circ} \mathrm{C}$ ) for temperature measurement of the combustion chamber and Bacharach smoke index equipment for smoke index measurement.

\section{Experimental procedure}

Wood chips, rice husk briquettes, pinecones and maize cobs were loaded into the metallic hopper from the top to calculate the performance of the different fuel types. Water was filled into the water seal to prevent leakage from the top. The fuel was ignited by a flame torch held below the grate through the ash pit door. As observed during the start-up, considerable amount of smoke was generated by the stove. As the fuel got ignited and the gasification proceeded the flame developed well at the bottom portion of the fuel, the flame is visible in the combustion chamber and smoke disappears from the chimney. The flame torch was then removed and the ash pit door was closed tightly. The amount of air entering the stove was controlled by the air damper provided at the primary air inlet. When high ash content fuel was used, such as rice husk briquette, dust removal was done by shaking the ash removal mechanism provided at the bottom of the grate.

\section{Efficiency calculation}

Efficiency measurements were tested by water boiling test method for a particular fuel.

A known quantity of water was heated on a cook stove in water boiling test. The quantity of water evaporated after complete burning

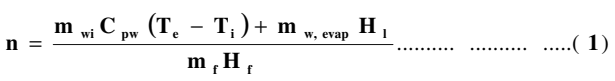

of the fuel was determined to calculate the efficiency by using the following formula:

$M_{w i}$ - mass of water initially in cooking vessel, $\mathrm{kg}$

$C_{p w}$ - specific heat of water, $\mathrm{kJ} / \mathrm{kg}{ }^{\circ} \mathrm{C}$

$M_{w, \text { evap }}$ - mass of water evaporated, $\mathrm{kg}$

$M_{f}$ - mass of fuel burned, $\mathrm{kg}$

$T_{e}$ - temperature of boiling water, ${ }^{\circ} \mathrm{C}$

$T_{i}$ - initial temperature of water in pot, ${ }^{\circ} \mathrm{C}$

$H_{l}$ - latent heat if evaporation at $100{ }^{\circ} \mathrm{C}$ and $105 \mathrm{~Pa}, \mathrm{~kJ} / \mathrm{kg}$

$H_{f}$ - calorific value of fuel, $\mathrm{kJ} / \mathrm{kg}$

\section{Assessments of economic prospects}

The prospects of the economical aspects and gains associated with the IGS-2F were determined by the exemplary analysis of the fuel saved by operating the IGS-2F. The prospects of reductions in medical expenses of the people would benefit by the elimination of morbidity and mortality caused by the smoke borne diseases was not dealt with.

\section{SOCIO ECONOMIC ANALYSIS}

The process of evaluation of economical aspects and gains associated with the institutional gasifier were determined by the basic exemplary analysis of the wood saved by the operation of gasifier stove instead of traditional stove. The payback period for the use of IGS-2F instead of traditional cooking stove is found to be 13 month 12 days. This means that the initial investment for the project will be earned back in just about 14 months. Since we have assume that the life of IGS-2F to be 8 years, IGS-2F earns saving for about six years and ten months which is a good result for any project.

The cost benefit ratio was also calculated and found to be 4.0 which is a very good result. The calculation however doesn't consider the 
quantified value of mortality associated with the smoke or pollution. It also doesn't consider saving of money which wcould be required for treating different diseases due to smoke or indoor air pollution.

\section{SOCIO CULTURAL ACCEPTABILITY}

The gasifier stove that is IGS-2F is a modified design and new concept in the context for Nepalese. The attraction of the stove will be high if it is timely commercialized because it produces far less pollution than traditional one.

It would be more worthy if it is used in instuitional areas of Nepal at hostels, hotels, schools where cooking is done for the large numbers of people. The design of the stove is simple and can be made with locally available material, therefore no problem in manufacturing it locally. The initial investment is NRs. 22,500 which is considered acceptable for institutional areas. If commercialized in large scale, cost may reduce by considerable amount.
It is therefore assumed that IGS-2F will be culturally accepted; however with some modification there need to be effective promotion programs to make it known to people in institutional areas and to encourage them to install it. It should emphasize the health benefits because of the low pollution emitted. Promotional program of IGS-2 should be encouraged.

\section{RESULTS AND DISCUSSIONS}

Table 1 shows the comparison of average efficiencies between the modified gasifier and newly fabricated gasifier. From which, the efficiency varies from $13.24 \%$ to $21.41 \%$. The maximum efficiency that was found out was $21.4 \%$ for pinecones for the modified gasifier. From the chart, it can be seen that the efficiencies for the rest of the fuel except pinecone, the efficiency of the newly fabricated gasifier was better than the modified gasifier. This might be due to the proper air inlet and gas outlet of the reaction/combustion chamber of the newly fabricated gasifier in comparison to the modified gasifier.

Table 1: Comparative average efficiency for the gasifier

\begin{tabular}{|l|l|c|c|}
\hline S.N. & Fuel material & $\begin{array}{l}\text { Efficiency of modified gasifier } \\
\text { (NAST) }\end{array}$ & $\begin{array}{l}\text { Efficiency of newly fabricated gasifier } \\
\text { (CRE) }\end{array}$ \\
\hline 1 & Rice husk briquette & 17.19 & 19.02 \\
\hline 2 & Wood chips & 13.24 & 17.84 \\
\hline 3 & Maize cob & 16.13 & 18.99 \\
\hline 4 & Pine cones & 21.41 & $\mathrm{NA}$ \\
\hline
\end{tabular}

\section{SMOKE INDEX TEST}

The smoke index test was done with the help of the Bacharach oil burner smoke apparatus and scale, which was developed in cooperation with the Shell Development Company. The sample of the smoke in filter paper was compared with the standard scale, which finds out the extent or level of pollution or smoke. If the smoke is in range one to three, the smoke pollution is in acceptable range but if the sample rises to the level of 4 the pollution is not acceptable. So the smoke index level in the range of $0-3$ is acceptable, 4-5 is critical and 6-9 is not acceptable. 

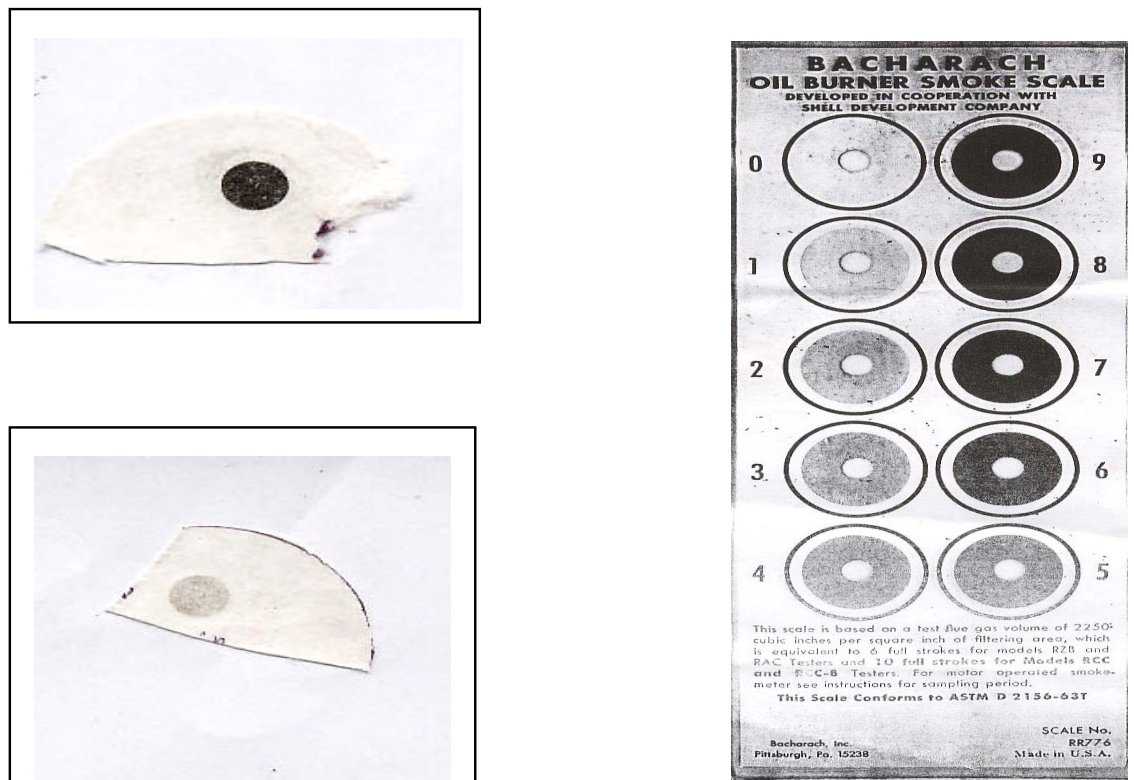

Figure 3 Smoke samples taken (Left), Bacharach oil burner smoke scale (Right)

During the test different samples were taken at different times of combustion; at the start or after $1^{\text {st }}$ minute of combustion then after 5 minutes, after 15 minutes and after 20 minutes. They were then compared with the scale as shown in figure 3 .It has been found that the level of pollution was very high during the initial stage of the ignition and as the combustion was smooth the smoke appeared to be clean and hence was in the acceptable range. It has been found that the level of smoke was very high especially for wood chips at the initial stage of the ignition compared to the other fuels. The level of smoke index was the lowest for maize cob throughout the combustion period.

\section{CONCLUSIONS}

- The efficiency of the newly fabricated gasifier was found to be more than that of the modified gasifier in all types of fuel tested.

- The efficiency of the institutional gasifier was found to be different with different types of fuels; for example for wood chips efficiency of IGS-2M was found to be $13.24 \%$ while the efficiency for IGS-2F was found to be $17.84 \%$ which is $4.6 \%$ higher. Maize cob efficiency in IGS-2F is higher than that of IGS-2M by $2.86 \%$. Similarly for rice husk briquette the efficiency for IGS-2F is $1.83 \%$ higher than that of IGS-2M, which has very little significance.

- Pine cones gave the highest efficiency comparative to that of other fuel types in case of IGS-2M.

- The saving in the fuel wood using IGS-2F instead of traditional cooking stoves was found to be $0.6575 \mathrm{~kg}$ per person per meal.

- The socio economic analysis found that the payback period is 14 month compared to that of traditional cooking stove. 
- The combustion process is smokeless which is advantageous towards the health aspect.

- The IGS is a versatile stove which can use different locally available fuels such as agro-forest residues, wood chips, briquettes etc.

\section{ACKNOWLEDGEMENT}

The authors would like to acknowledge the technical cooperation and guidance provided by Dr. Ramesh Man Singh (NAST) and financial support provided by Center for Renewable Energy (CRE), Jwagol, Lalitpur.

\section{REFERENCES}

[1] Basnyat, M.S, 2004, "A study on gasifier based drying of large cardamom: a case study of Ilam District", MSc. Thesis, Department of Mechanical Engineering, Pulchowk Campus, Tribhuvan University, Nepal.

[2] Shrestha, R., Neupane, S., Niroula, S. and Joshi, S., 2005, "Water pasteurizing unit for an improved cooking stoves", B.E. Project, Department of Mechanical Engineering, Pulchowk Campus, Tribhuvan University, Nepal.

[3] Simkhada, K.P, 2005, M.Sc, Thesis, "A Study on the Performance of a Domestic Gasifier Stove", Department of Mechanical Engineering, Pulchowk Campus, Tribhuvan University Nepal.

[4] Singh, R.M. and Shakya G. R., 2001, "Study of the biomass briquetting systems and cooking devices", A regional Research and dissemination program phase II, Asian Institute of Technology (AIT), Bangkok, Thailand. 
